Article

\title{
The New Cooperative Medical Scheme and Self-Employment in Rural China
}

\author{
Baozhong Su ${ }^{1, *}$, Gatwaza Hategekimana Thierry ${ }^{1}$, Qihui Chen ${ }^{2}$ and Qiran Zhao ${ }^{2}$ \\ 1 College of Economics and Management, China Agricultural University, Beijing 100083, China; \\ gtiti2008@hotmail.com \\ 2 Center for Food and Health Economic Research, College of Economics and Management, \\ China Agricultural University, Beijing 100083, China; chen1006@umn.edu (Q.C.); zhaoqiran@139.com (Q.Z.) \\ * Correspondence: sbz@cau.edu.cn; Tel.: +86-10-6273-8685
}

Academic Editors: Hongbo Liu, Sizhong Sun and Iain Gordon

Received: 29 October 2016; Accepted: 14 February 2017; Published: 22 February 2017

\begin{abstract}
Using panel data from the China Health and Nutrition Survey, this study estimates the effect of the New Cooperative Medical Scheme (NCMS) on self-employment in rural China, based on a difference-in-differences method (combined with propensity score matching). Specifically, we compare employment status of the participants and non-participants groups before and after the NCMS was implemented (within the common-support region). We found that the NCMS increased a rural resident's likelihood of shifting from working for others to self-employed by 38 percentage points and that of shifting from temporarily employed to self-employed by 23 percentage points. These results suggest that apart from reducing uncertainty in future spending for the insured due to catastrophic illness, universal health insurance could also have a positive effect on the labor market, namely, that of increasing rates of self-employment.
\end{abstract}

Keywords: universal health insurance; self-employment; difference-in-differences; propensity score matching; rural China

\section{Introduction}

It has been recognized that entrepreneurship is an active promoting factor for a growing economy [1-4]. Not only do entrepreneurs create new firms for themselves, but they also create new employment opportunities for others [2]. As a form of entrepreneurship, self-employment has been a sign of economic progress since China's economic reform in the 1970s. In particular, it has been found that earnings from self-employed work, in the forms of traders, merchants, and household-run businesses, etc., contributed greatly to the rapid increases in China's rural incomes in the late 1980s and 1990s [3,4]. The incidence of self-employment can be influenced by many factors, health insurance included. As a tool to prevent the insured from falling into poverty due to serious illness, health insurance serves to reduce the uncertainty of future spending, whereby increasing savings for investments, which in turn improves the prospect of self-employment.

However, there are currently two contrasting views regarding the causal link between health insurance and self-employment. One view argues for a positive link because unemployed individuals with access to spousal health insurance are found to be more likely to become self-employed than those without [5]. The other argues for a negative link, in that people are more likely to work for companies that provide employer-sponsored insurance than to create their own business-as business owners, they would need to spend more on health care [6-8]. Although the New Rural Cooperative Medical Scheme (NCMS) has been implemented in rural China for more than a decade, which of the two views better describes its impact on entrepreneurship remains unknown. 
This paper fills this gap by empirically estimating the effect of NCMS coverage on the incidence of self-employment among rural Chinese residents. Using a panel dataset from the China Health and Nutrition Survey, our difference-in-differences analysis combined with propensity score matching found that NCMS enrollment increased a rural resident's likelihood of shifting from working for others to self-employed by 38 percentage points and that of shifting from temporarily employed to self-employed by 24 percentage points. Not only do these results lend empirical support to the first view discussed above, but they also suggest that apart from increasing consumption and savings for rural residents found in previous studies [9-11], health insurance also helps to promote entrepreneurship in rural China.

\section{Literature Review}

Despite the two contrasting views regarding the causal link between health insurance and self-employment discussed above, many empirical studies, especially those conducted in the United States, found a positive link. For example, using a difference-in-differences (DD) method, Currie and Madrian (1999) found that a lack of health insurance accounts for a $25 \%$ reduction in business creation [12]. Echoing this finding, Heimb and Lurie (2011) found a positive effect of tax-based subsidies for self-employed health insurance on self-employment [13]. Moreover, Wellington (2001) found that unemployed individuals with access to their spouse's health insurance program are more likely to become self-employed than those without [5]. More specifically, the availability of spousal coverage increases the probability of an individual being self-employed by $2.3-4.6$ percentage points. Based on these results, Wellington predicted that universal health coverage could increase self-employment in the workforce. Fairlie et al. (2011) also found that spousal coverage acts to enlarge the impact of health insurance on business creation: it is considerably larger for individuals with spousal coverage than for those without spousal coverage [7]. Examining this issue from a different angle, Cai and Minniti (2011) found that employer-provided health insurance is negatively correlated to the likelihood of self-employment, "locking" employees in their current jobs [8], which implies that other types of health insurance programs (e.g., government-provided ones) may be able to create self-employment. (Note that not all studies found positive effects of health insurance on self-employment. For example, using data from 1984-1986 panels of the Survey of Income and Program Participation (SIPP), Holtz-Eakin et al. (1996) examined whether the availability of an alternative source of health insurance increases the probability of self-employment but found no significant impact [14].)

However, whether these positive impacts can be generalized to include the case of rural China is unclear, one reason being that the NCMS and most of the American programs are different in some fundamental features. In particular, unlike those employer-provided programs in the United States, the NCMS is provided by the government to the entire rural population, regardless of individuals' employment status (see below for more details). Thus, empirical scrutiny on the impact of NCMS coverage in China is needed.

To date, empirical studies linking NCMS enrollment and entrepreneurship in the context of rural China are largely non-existent. Whereas existing studies have examined the effects of NCMS enrollment on household nutrient-intake structure [9], durable goods consumption [10], savings [11] and labor migration [15], none has focused on it impact on the incidence of self-employment. To the best of our knowledge, the present paper is the first to examine the impact of NCMS coverage on self-employment.

\section{Background}

The old Cooperative Medical Scheme (CMS) was established in rural China during the collective era in the 1950s. The scheme was financed at the village and commune levels, aiming to provide nearly-free preventive and curative care to farmers. However, the CMS lost its funding sources along with the collapse of China's collective system in the late 1970s [16]. Despite various attempts to rebuild a health insurance system in rural China, the majority of rural residents remained uninsured between 
1985 and 2003. In particular, throughout the 1990s, less than $10 \%$ of residents and less than $20 \%$ of households in rural China had health insurance coverage [16].

In 2002, the Chinese government approved a new initiative to gradually establish a universal health insurance program, the New Rural Cooperative Medical system, aiming to protect households from falling into poverty due to catastrophic payments that result from poor health [17]. Launched in 2003, the NCMS planned to cover 840 million residents in rural China [18]. In 2009, the Chinese government announced the goal of universal coverage of basic healthcare for all citizens by 2020, through major reforms in the public health system, medical care delivery system, health security system and pharmaceutical system [19]. Such a goal helps to enhance the already existing health insurance schemes, including the NCMS.

Compared to the old scheme, the new scheme has three distinctive features. Firstly, unlike the CMS, the enrollment of NCMS is made voluntary. To make it fairer and financially more attractive to low-income households, household contributions are supplemented by government subsidies [20]. Secondly, the new scheme is operating at the county level, rather than at the village level as in the old scheme [21]. The village-level services provided by the CMS were mostly basic ones, relying heavily on traditional Chinese medicine [16]. In contrast, under the new scheme, there is considerable heterogeneity in the specific services covered (especially out-patient and inpatient services) across counties. Finally, the NCMS requires the unit of enrollment to be households rather than individuals, in order to reduce (within-household) adverse selection that may occur at the individual level.

Upon inception, the coverage of the NCMS expanded quickly, from 3\% in 2004 to $40.6 \%$ in 2006 [22]. It reached $94.2 \%$ of the targeted population in 2009 [18] and $96 \%$ in 2011 [17]. Recent research revealed that access to the NCMS has improved household consumption of durable goods [12] and has increased household savings in rural China [14]. However, whether it serves to encourage self-employment has never been examined. This paper attempts to shed some light on this issue.

\section{Data}

The data analyzed in this paper come from the China Health and Nutrition Survey (CHNS), a longitudinal project collaborated among the Carolina Population center at the University of North Carolina at Chapel Hill, the Institute of Nutrition and Food Hygiene, and the Academy of Preventive Medicine in China. Ten waves of survey were conducted between 1989 and 2014. In 1989, a multistage cluster sampling was used to select a representative sample of residents in 8 Chinese provinces, namely, Heilongjiang, Jiangsu, Shandong, Henan, Hubei, Hunan, Guangxi and Guizhou, covering some 4400 households and 20,000 individuals.

Since the NCMS was introduced in 2003 and reached nearly universal coverage in 2009, we use information on only adults in the labor force (with a total of 9020 observations) from the 2000 wave (baseline period) and the 2006 (evaluation period) to evaluate its impact. A number of sample restrictions were applied for the purpose of this paper. First, since the NCMS concerns only rural residents, we include only individuals whose residential area was classified as "rural village" or "suburban village" in the analysis-1738 observations from "city" and "town" areas were thus dropped. Second, to avoid confounding the effects of the NCMS with other health insurance programs, we further excluded 398 observations from the analysis, who were not enrolled in the NCMS but had access to other health insurance programs (including Free Medical Insurance, Workers Compensation, Insurance for Family Members, Unified Planning Medical, Health for Women and Children, and Expanded Program of Immunization for children). The final analytical sample includes 6884 observations.

To facilitate regression analysis, we subdivide one's employment status into four categories: "unemployed", "temporarily employed", "self-employed" and "working for others". Specifically, the "unemployed" category includes individuals who did not have a job but were seeking for one at the time of survey. The "temporarily employed" are those who were engaged in temporary activities, including farming activities. Only individuals who are owners of enterprises are considered to be "self-employed". A self-employed individual can be an owner-manager with employees or an 
independent operator with no employees. Finally, individuals who were employed but did not own the business are defined as "working for others". This category includes permanent employees of enterprises, contractors with employers and family workers.

\section{Method}

With observations from both the baseline and evaluation periods being available, we are able to estimate the impact of NCMS enrollment on self-employment using a difference-in-differences method. Specifically, let $T_{i}$ denote the time period in which an individual $i$ is observed: $T_{i}=0$ if before the NCMS started (i.e., 2000) and $T_{i}=1$ if after the NCMS started (i.e., 2006). Further, let $P_{i}$ denote two groups of individuals with respect to their NCMS enrollment status. The treatment group $\left(P_{i}=1\right)$ includes those who were enrolled in the NCMS in 2006 (but not enrolled in 2000); the control group $\left(P_{i}=0\right)$ includes individuals who were not covered by the NCMS in either 2000 or 2006. Finally, let $Y_{i}$ denote whether an individual is self-employed ( $Y_{i}=1$ if self-employed and $Y_{i}=0$, otherwise).

Consider first the single difference (SD) in individual $i$ 's employment status, $Y_{i}$, before and after the NCMS started, for the treatment group:

$$
\mathrm{SD}^{\text {Treatment }} \equiv \mathrm{E}\left[Y_{i} \mid T_{i}=1, P_{i}=1\right]-\mathrm{E}\left[Y_{i} \mid T_{i}=0, P_{i}=1\right]
$$

While $\mathrm{SD}^{\text {Treatment }}$ captures the impact of the NCMS, it may capture something extra, because (confounding) factors other than NCMS coverage, such as the development of or fluctuations in China's rural economy in general, may have also affected one's employment status between the baseline and evaluation periods. Yet noticing that the baseline-evaluation difference in $Y_{i}$ for the control group, $\mathrm{SD}^{\text {Control }} \equiv \mathrm{E}\left[Y_{i} \mid T_{i}=1, P_{i}=0\right]-\mathrm{E}\left[Y_{i} \mid T_{i}=0, P_{i}=0\right]$, is presumably not affected by the NCMS but captures the influences of "all other factors", we can subtract $\mathrm{SD}^{\text {Control }}$ from $\mathrm{SD}^{\text {Treatment }}$ to help eliminate the impact of those confounding factors, whereby isolating the impact of NCMS coverage. This gives rise to a difference-in-difference (DD) estimator:

$$
\mathrm{DD} \equiv\left\{\mathrm{E}\left[Y_{i} \mid T_{i}=1, P_{i}=1\right]-\mathrm{E}\left[Y_{i} \mid T_{i}=0, P_{i}=1\right]\right\}-\left\{\mathrm{E}\left[Y_{i} \mid T_{i}=1, P_{i}=0\right]-\mathrm{E}\left[Y_{i} \mid T_{i}=0, P_{i}=0\right]\right\}
$$

This double-difference (difference-in-difference) can be estimated using a linear regression model:

$$
Y_{1}=\alpha+\beta T_{\mathrm{i}}+\gamma P_{i}+\sigma\left(T_{i} \times P_{i}\right)+u,
$$

where $T_{i} \times P_{i}$ is the interaction between the time dummy $T_{i}$ and the group dummy $P_{i}, u$ is the error term and the parameter $\sigma$ captures the difference-in-differences estimate, DD, derived in Equation (2). In estimation, a set of observed (pre-determined) characteristics $\mathbf{X}$ (including age, gender, ethnicity and education, etc.) is added to help control for partly the differences in the secular trend between the treatment and control groups.

Equation (3) is estimated separately for individuals falling to different employment categories defined above, i.e., "working for others", "temporarily employed", and "unemployed". The dependent variable in each category is matched separately with "self-employed" $\left(Y_{i}=1\right)$ and assigned the value 0 (i.e., $Y_{i}=0$ ). In other words, we have three different dependent variables for which we run three separate regressions.

Note that the validity of the DD estimate based on Equation (3) hinges on the validity of the standard parallel-trend assumption: that the change in $Y$ between the baseline and evaluation periods is the same for both groups in the absence of the NCMS. To check whether this assumption is plausible, we perform a falsification test below, using two pre-NCMS data sets (from the 1997 and 2000 waves) to perform a DD analysis.

To further reduce the impacts of time-varying unobservables, we combine the DD analysis with a propensity score matching (PSM) procedure. Specifically, we first estimate a logit model predicting one's NCMS enrollment using the set of aforementioned observed characteristics $\mathbf{X}$, and then perform 
a DD analysis on the common support constructed from the first-step estimated propensity scores. It is worth pointing out, however, that given a limited set of observed characteristics, our DD-PSM estimates may still be subject to bias due to unobserved time-varying factors.

\section{Results}

Before turning to the main result of this paper, recall that the validity of the DD, i.e., Equation (3), hinges on the validity of the parallel-trend assumption. To test it, we conduct a falsification test using observations from the 1997 and 2000 waves of the CHNS, which are both pre-NCMS periods. If the parallel-trend assumption is plausible, then a DD analysis "pretending" the 2000 wave as the post-NCMS evaluation period would yield an insignificant impact of the "fake" NCMS on self-employment. Consistent with this expectation, Table 1 indicates that the DD estimates of impacts of (fake) NCMS enrollment (i.e., coefficients on $P \times T$ ) are essentially zero for all employment subcategories. This lends strong support to the parallel-trend assumption.

Table 1. Results of falsification tests.

\begin{tabular}{cccc}
\hline \multirow{2}{*}{ Dependent Variable } & $\begin{array}{c}\mathbf{( 1 )} \\
\text { Work for Others to } \\
\text { Self-Employed }\end{array}$ & $\begin{array}{c}\mathbf{( 2 )} \\
\text { Temporarily Employed to } \\
\text { Self-Employed }\end{array}$ & $\begin{array}{c}\mathbf{( 3 )} \\
\text { Unemployed to } \\
\text { Self-Employed }\end{array}$ \\
\hline \multirow{2}{*}{$\times T$} & 0.003 & 0.010 & 0.001 \\
& $(0.17)$ & $(0.76)$ & $(0.09)$ \\
$T$ & 0.004 & $-0.039^{* * *}$ & -0.003 \\
$P$ & $(0.63)$ & $(7.60)$ & $(1.01)$ \\
& $0.091^{* * *}$ & $0.048^{* * *}$ & 0.012 \\
Age & $(5.67)$ & $(3.97)$ & $(1.60)$ \\
& $0.002^{* * *}$ & $0.003 * 000$ & $(2.70)$ \\
Gender & $(5.27)$ & $(11.90)$ & -0.001 \\
Education: & $0.027^{* * *}$ & 0.008 & $(0.14)$ \\
Primary & $(2.92)$ & $(1.17)$ & -0.005 \\
& & & $(0.84)$ \\
Lower secondary & $-0.036^{* * *}$ & 0.008 & -0.009 \\
& $(2.81)$ & $(0.93)$ & $(1.49)$ \\
Upper secondary & $-0.115^{* * *}$ & -0.010 & $-0.030 * * *$ \\
& $(8.34)$ & $(0.97)$ & $(3.35)$ \\
University & $-0.318^{* * *}$ & $-0.047^{* * *}$ & 0.012 \\
Ethnicity dummies & $(17.68)$ & $(3.29)$ & $(0.14)$ \\
Province dummies & $-0.758^{* * *}$ & 0.081 & yes \\
$\mathrm{R}^{2}$ & $(12.85)$ & $(0.62)$ & yes \\
Observations & yes & yes & 0.03 \\
& yes & yes & 5889 \\
\hline
\end{tabular}

Note: $t$-values in parentheses. ${ }^{* * *}, * *$, and ${ }^{*}$ denote statistical significance at the $1 \%, 5 \%$, and $10 \%$ levels, respectively.

Yet even if the parallel-trend assumption is plausible, the DD method may still be subject to bias due to time-varying unobservables. To reduce this problem, we combine our DD analysis with a propensity score matching procedure.

In the first step, we use individuals' age, gender, education and ethnicity as the matching variables. Given the relatively limited number of matching variables, we use all of these variables for all three models (Model 1: from working for others to self-employed; Model 2: from temporarily employed to self-employed; Model 3: from unemployed to self-employed). The matching is based on a 1:1 nearest neighbor matching algorithm, discussed in Abadie and Imbens (2006) [23]. For Models 1, 2 and 3, respectively, 1486, 1425 and 1339 pairs of individuals are matched. The distributions of the observed characteristics before and after matching for these models are presented in Tables A1-A4 in the Appendix A.

The main results of our DD-PSM analyses are presented in Table 2, where odd-numbered columns report the first-step logit regressions and even-numbered ones report the associated DD-PSM results. 
(For ease of comparison, we also present our DD results in Table A5 in the Appendix A). Our results indicate that enrollment in the NCMS increased a rural resident's likelihood of shifting from working for others to self-employed by 38 percentage points and that of shifting from temporarily employed to self-employed by 24 percentage points. In contrast, enrollment in the NCMS has only a statistically insignificant impact on the probability of one's shifting from unemployed to self-employed. These results suggest that individuals who work for others may have saved some share of their income in order to prepare for unexpected health shocks, and the NCMS helps reduce some income risks and precautionary savings, which in turn increases the willingness of employed individuals to create their own business. The effect is smaller for the temporarily employed, presumably because their overall income and savings are lower than those full-time employees. The NCMS has little impact for unemployed individuals, as they may have little or no savings, which renders it difficult for them to afford startup capital for their own business.

Table 2. Main results.

\begin{tabular}{|c|c|c|c|c|c|c|}
\hline \multirow[b]{2}{*}{$\begin{array}{c}\text { Dependent } \\
\text { Variable }\end{array}$} & \multicolumn{2}{|c|}{ Model 1} & \multicolumn{2}{|c|}{ Model 2} & \multicolumn{2}{|c|}{ Model 3} \\
\hline & $\begin{array}{l}(1) \\
\text { Enrolled in } \\
\text { NCMS }\end{array}$ & $\begin{array}{c}\text { (2) } \\
\text { Work for } \\
\text { Others to } \\
\text { Self-Employed }\end{array}$ & $\begin{array}{c}(3) \\
\text { Enrolled } \\
\text { in NCMS }\end{array}$ & $\begin{array}{c}\text { (4) } \\
\text { Temporarily } \\
\text { Employed to } \\
\text { Self-Employed }\end{array}$ & $\begin{array}{c}(5) \\
\text { Enrolled } \\
\text { in NCMS }\end{array}$ & $\begin{array}{c}\text { (6) } \\
\text { Unemployed to } \\
\text { Self-Employed }\end{array}$ \\
\hline Method & Logit & DD-PSM & Logit & DD-PSM & Logit & DD-PSM \\
\hline$P \times T$ & & $\begin{array}{c}0.38^{* * *} \\
(8.42)\end{array}$ & & $\begin{array}{c}0.23^{* * *} \\
(4.76)\end{array}$ & & $\begin{array}{c}0.01 \\
(0.39)\end{array}$ \\
\hline$T$ & & $\begin{array}{c}-0.40 * * * \\
(9.21)\end{array}$ & & $\begin{array}{c}-0.29^{* * *} \\
(6.05)\end{array}$ & & $\begin{array}{l}-0.03 \\
(1.02)\end{array}$ \\
\hline$P$ & & $\begin{array}{c}0.05^{* * *} \\
(3.17)\end{array}$ & & $\begin{array}{c}0.02 \\
(1.25)\end{array}$ & & $\begin{array}{l}0.003 \\
(0.42)\end{array}$ \\
\hline Age & $\begin{array}{l}0.03^{* * *} \\
(10.77)\end{array}$ & & $\begin{array}{l}0.04^{* * *} \\
(11.84)\end{array}$ & & $\begin{array}{l}0.03^{* * *} \\
(10.48)\end{array}$ & \\
\hline Gender & $\begin{array}{c}0.05 \\
(0.69)\end{array}$ & & $\begin{array}{c}0.11 \\
(1.50)\end{array}$ & & $\begin{array}{c}0.04 \\
(0.61)\end{array}$ & \\
\hline Education: & & & & & & \\
\hline Primary & $\begin{array}{c}0.29^{* * *} \\
(3.01)\end{array}$ & & $\begin{array}{l}0.34^{* * *} \\
(11.78)\end{array}$ & & $\begin{array}{c}0.29 * * * \\
(3.05)\end{array}$ & \\
\hline Lower secondary & $\begin{array}{c}0.33 * * * \\
(3.30)\end{array}$ & & $\begin{array}{c}0.42 * * * \\
(4.02)\end{array}$ & & $\begin{array}{c}0.40 * * * \\
(3.82)\end{array}$ & \\
\hline Upper secondary & $\begin{array}{c}0.43^{* * *} \\
(3.43)\end{array}$ & & $\begin{array}{c}0.59^{* * *} \\
(4.27)\end{array}$ & & $\begin{array}{c}0.62 * * * \\
(4.34)\end{array}$ & \\
\hline University & $\begin{array}{c}-0.83^{* *} \\
(2.24)\end{array}$ & & $\begin{array}{l}1.41^{*} \\
(0.78)\end{array}$ & & $\begin{array}{l}1.39 * \\
(1.78)\end{array}$ & \\
\hline Ethnicity dummies & yes & & yes & & yes & \\
\hline $\begin{array}{l}\text { Province dummies } \\
\text { Log likelihood/R } R^{2}\end{array}$ & $\begin{array}{c}\text { yes } \\
-2785.60\end{array}$ & 0.10 & $\begin{array}{c}\text { yes } \\
-2578.10\end{array}$ & 0.06 & $\begin{array}{c}\text { yes } \\
-2431.39\end{array}$ & 0.02 \\
\hline Observations & 4503 & 2972 & 4119 & 2850 & 3864 & 2678 \\
\hline
\end{tabular}

Note: $t$-valuesin parentheses. ${ }^{* * *}, * *$, and ${ }^{*}$ denote statistical significance at the $1 \%, 5 \%$, and $10 \%$ levels, respectively.

\section{Conclusions}

This paper aims to investigate the impacts of universal health insurance on self-employment, taking the New Cooperative Medical Scheme in rural China as a case study. Using a difference-in-differences method (combined with propensity score matching), our estimation results show that there is a sizable and statistically significant positive relationship between NCMS coverage and self-employment in rural China. Nevertheless, the impacts of NCMS coverage differ greatly for individuals in different baseline employment categories. Specifically, the NCMS has a significant effect on the temporarily employed and those working for others, while it has an insignificant effect on the unemployed. Serving as a complement to previous findings that NCMS enrollment increases rural households' consumption and savings [9-11], our results suggest that the NCMS can also affect the development of rural labor markets. Given the many benefits that are generated by the NCMS, the government of China should strengthen its functionality and stabilize its implementation. 
The findings of this study may also be relevant for developing countries in which universal health insurance has not yet been provided.

However, a note on the limitations of our study is in order. While the difference-in-differences method eliminates the influence of time invariant factors and the propensity score matching procedure reduces the problem of "selection on observables", our estimates may still be subject problems given rise by unobserved time-varying factors, such as fluctuations in the conditions of local labor markets. Caution is thus needed when interpreting our empirical results.

Before closing, we point out a number of directions for future research. First, although the NCMS is found to increase self-employment, whether it also helps stabilize one's own business remains unclear. While it is probably still too early to examine the long-run effects of the NCMS, future research should shed some light on this issue when more data become available. Second, the CHNS data do not allow us to study the impact of NCMS coverage on specific types of self-employed business (e.g., traders, merchants or household-run restaurants or stores). Yet to the extent that different businesses have different levels of profitability, future studies on the impacts of NCMS coverage on the creation of specific forms of self-employed businesses, as well as the associated profits, could be useful for assessing the economic benefits generated by the NCMS more fully.

Acknowledgments: The authors gratefully acknowledge the valuable comments and suggestions by Noella Karemera Umuhoza, Clement Olivier, Jean Yves Kubwimana, Rene Paul, Immaculee Twendereye, Pierre Claver Gatwaza, Aline Umutoni and Nizere Zikama Ignace as well as participants of the 7th CAER-IFPRI Annual Conference in Lin'an, China, and the financial support by National Science Foundation of China (Grants: 71603261), the Ministry of Education of Humanities and Social Science project (Grants: 16YJC880107), the Fundamental Research Funds for the Central Universities, China Agricultural Foundation 'Da Bei Nong Education Fund'. Besides, this research uses data from China Health and Nutrition Survey (CHNS), so we thank the National Institute for Nutrition and Health, China Center for Disease Control and Prevention, Carolina Population Center (P2C HD050924, T32 HD007168), the University of North Carolina at Chapel Hill, the NIH (R01-HD30880, DK056350, R24 HD050924, and R01-HD38700) and the NIH Fogarty International Center (D43 TW009077, D43 TW007709) for financial support for the CHNS data collection and analysis files from 1989 to 2015 and future surveys, and the China-Japan Friendship Hospital, Ministry of Health for support for CHNS 2009, Chinese National Human Genome Center at Shanghai since 2009, and Beijing Municipal Center for Disease Prevention and Control since 2011. Any remaining errors are solely our responsibility.

Author Contributions: Conceived and designed the experiments: Baozhong Su; Performed the experiments: Gatwaza Hategekima Thierry, Baozhong Su; Analyzed the data: Baozhong Su, Gatwaza Hategekima Thierry; Qiran Zhao; Contributed reagents/materials/analysis tools: Gatwaza Hategekima Thierry; Qihui Chen; Wrote the paper: Baozhong Su, Gatwaza Hategekima Thierry.

Conflicts of Interest: The authors declare no conflict of interest.

\section{Appendix A}

Table A1. Pre-Matching distributions of observed characteristics.

\begin{tabular}{|c|c|c|c|c|c|c|c|c|}
\hline & \multicolumn{2}{|c|}{$\begin{array}{c}\text { (1) } \\
\text { Work for Others }\end{array}$} & \multicolumn{2}{|c|}{$\begin{array}{c}(2) \\
\text { Temporarily Employed }\end{array}$} & \multicolumn{2}{|c|}{$\begin{array}{c}\text { (3) } \\
\text { Unemployed }\end{array}$} & \multicolumn{2}{|c|}{$\begin{array}{c}\text { (4) } \\
\text { Self-Employed }\end{array}$} \\
\hline & Treat-ment & Control & Treat-ment & Control & Treat-ment & Control & Treat-ment & Control \\
\hline Age & $\begin{array}{c}39.16 \\
(10.44)\end{array}$ & $\begin{array}{c}36.26 \\
(12.19)\end{array}$ & $\begin{array}{c}42.15 \\
(13.14)\end{array}$ & $\begin{array}{c}30.12 \\
(11.43)\end{array}$ & $\begin{array}{c}45.88 \\
(16.14)\end{array}$ & $\begin{array}{c}37.14 \\
(14.16)\end{array}$ & $\begin{array}{c}45.82 \\
(11.94)\end{array}$ & $\begin{array}{c}41.36 \\
(13.68)\end{array}$ \\
\hline Gender & $\begin{array}{c}0.34 \\
(0.47)\end{array}$ & $\begin{array}{c}0.37 \\
(0.48)\end{array}$ & $\begin{array}{c}0.43 \\
(0.50)\end{array}$ & $\begin{array}{c}0.44 \\
(0.50)\end{array}$ & $\begin{array}{c}0.30 \\
(0.47)\end{array}$ & $\begin{array}{c}0.42 \\
(0.50)\end{array}$ & $\begin{array}{l}0.49 \\
(0.5)\end{array}$ & $\begin{array}{c}0.51 \\
(0.50)\end{array}$ \\
\hline Education: & & & & & & & & \\
\hline Primary & $\begin{array}{c}0.14 \\
(0.35)\end{array}$ & $\begin{array}{c}0.13 \\
(0.34)\end{array}$ & $\begin{array}{c}0.30 \\
(0.46)\end{array}$ & $\begin{array}{c}0.20 \\
(0.40)\end{array}$ & $\begin{array}{c}0.07 \\
(0.45)\end{array}$ & $\begin{array}{c}0.28 \\
(0.45)\end{array}$ & $\begin{array}{c}0.31 \\
(0.46)\end{array}$ & $\begin{array}{c}0.30 \\
(0.46)\end{array}$ \\
\hline Lower secondary & $\begin{array}{c}0.45 \\
(0.50)\end{array}$ & $\begin{array}{c}0.43 \\
(0.50)\end{array}$ & $\begin{array}{c}0.46 \\
(0.50)\end{array}$ & $\begin{array}{c}0.60 \\
(0.49)\end{array}$ & $\begin{array}{c}0.43 \\
(0.50)\end{array}$ & $\begin{array}{c}0.36 \\
(0.48)\end{array}$ & $\begin{array}{c}0.33 \\
(0.47)\end{array}$ & $\begin{array}{c}0.36 \\
(0.48)\end{array}$ \\
\hline Upper secondary & $\begin{array}{c}0.33 \\
(0.47)\end{array}$ & $\begin{array}{c}0.29 \\
(0.46)\end{array}$ & $\begin{array}{c}0.10 \\
(0.31)\end{array}$ & $\begin{array}{c}0.16 \\
(0.37)\end{array}$ & $\begin{array}{c}0.27 \\
(0.45)\end{array}$ & $\begin{array}{c}0.22 \\
(0.42)\end{array}$ & $\begin{array}{c}0.10 \\
(0.29)\end{array}$ & $\begin{array}{c}0.07 \\
(0.26)\end{array}$ \\
\hline University & $\begin{array}{c}0.03 \\
(0.17)\end{array}$ & $\begin{array}{c}0.10 \\
(0.30)\end{array}$ & - & - & - & - & $\begin{array}{c}0.003 \\
(0.001)\end{array}$ & $\begin{array}{l}0.001 \\
(0.03)\end{array}$ \\
\hline Observations & 189 & 594 & 127 & 251 & 33 & 65 & 1394 & 2707 \\
\hline
\end{tabular}

Note: Standard deviations in parentheses. We also include 8 ethnicity dummies in the set of the matching variables, but we do not report their distributions to avoid cluttering the table. Results are available upon request. 
Table A2. Post-Matching distributions of observed characteristics for Model 1.

\begin{tabular}{cccccccccc}
\hline & \multicolumn{3}{c}{$\mathbf{( 1 )} \begin{array}{c}\text { Work for Others } \\
\text { Treatment }\end{array}$} & \multicolumn{2}{c}{ Control } & \multicolumn{3}{c}{ (2) Self-Employed } \\
& Treatment & \multicolumn{2}{c}{ Control } \\
\hline Age & 39.08 & $(10.30)$ & 41.42 & $(11.7)$ & 45.69 & $(11.91)$ & 46.57 & $(12.93)$ \\
Gender & 0.33 & $(0.47)$ & 0.36 & $(0.48)$ & 0.49 & $(0.50)$ & 0.52 & $(0.50)$ \\
Primary & 0.14 & $(0.35)$ & 0.16 & $(0.37)$ & 0.31 & $(0.46)$ & 0.30 & $(0.46)$ \\
Lower secondary & 0.45 & $(0.50)$ & 0.36 & $(0.48)$ & 0.33 & $(0.47)$ & 0.30 & $(0.46)$ \\
Upper secondary & 0.33 & $(0.47)$ & 0.30 & $(0.46)$ & 0.09 & $(0.03)$ & 0.05 & $(0.23)$ \\
University & 0.03 & $(0.17)$ & 0.13 & $(0.33)$ & 0.003 & $(0.06)$ & 0.001 & $(0.03)$ \\
Observations & \multicolumn{2}{c}{177} & \multicolumn{2}{c}{298} & \multicolumn{2}{c}{1309} & \multicolumn{2}{c}{1188} \\
\hline
\end{tabular}

Note: Standard deviations in parentheses. We also include 8 ethnicity dummies in the set of the matching variables, but we do not report their distributions to avoid cluttering the table. Results are available upon request.

Table A3. Post-Matching distributions of observed characteristics for Model 2.

\begin{tabular}{cccccccccc}
\hline & \multicolumn{2}{c}{ (1) } & \multicolumn{2}{c}{ Temporarily Employed } & \multicolumn{3}{c}{ (2) Self-Employed } \\
& \multicolumn{2}{c}{ Treatment } & \multicolumn{2}{c}{ Control } & \multicolumn{2}{c}{ Treatment } & \multicolumn{2}{c}{ Control } \\
\hline Age & 42.2 & $(13.23)$ & 36.07 & $(12.36)$ & 45.69 & $(11.91)$ & 46.42 & $(13.1)$ \\
Gender & 0.43 & $(0.50)$ & 0.34 & $(0.48)$ & 0.49 & $(0.50)$ & 0.52 & $(0.50)$ \\
Primary & 0.30 & $(0.46)$ & 0.22 & $(0.42)$ & 0.31 & $(0.46)$ & 0.29 & $(0.46)$ \\
Lower secondary & 0.46 & $(0.50)$ & 0.53 & $(0.5)$ & 0.33 & $(0.47$ & 0.31 & $(0.46)$ \\
Upper secondary & 0.10 & $(0.31)$ & 0.21 & $(0.41)$ & 0.09 & $(0.03)$ & 0.08 & $(0.27)$ \\
University & - & - & - & - & 0.003 & $(0.06)$ & 0.002 & $(0.04)$ \\
Observations & & 116 & & \multicolumn{2}{c}{95} & \multicolumn{2}{c}{1309} & \multicolumn{2}{c}{1330} \\
\hline
\end{tabular}

Note: Standard deviations in parentheses. We also include 8 ethnicity dummies in the set of the matching variables, but we do not report their distributions to avoid cluttering the table. Results are available upon request.

Table A4. Post-Matching distributions of observed characteristics for Model 2.

\begin{tabular}{cccccccccc}
\hline & \multicolumn{3}{c}{ (1) } & Unemployed & \multicolumn{3}{c}{ (2) Self-Employed } \\
& \multicolumn{2}{c}{ Treatment } & \multicolumn{2}{c}{ Control } & \multicolumn{2}{c}{ Treatment } & \multicolumn{2}{c}{ Control } \\
\hline Age & 46.01 & $(16.67)$ & 43.69 & $(14.28)$ & 45.69 & $(11.91)$ & 46.13 & $(13.12)$ \\
Gender & 0.30 & $(0.47)$ & 0.36 & $(0.49)$ & 0.49 & $(0.50)$ & 0.5 & $(0.50)$ \\
Primary & 0.07 & $(0.25)$ & 0.21 & $(0.42)$ & 0.31 & $(0.46)$ & 0.29 & $(0.45)$ \\
Lower secondary & 0.43 & $(0.50)$ & 0.21 & $(0.42)$ & 0.33 & $(0.47)$ & 0.32 & $(0.47)$ \\
Upper secondary & 0.27 & $(0.45)$ & 0.35 & $(0.49)$ & 0.09 & $(0.03)$ & 0.08 & $(0.27)$ \\
University & 0.03 & $(0.17)$ & 0.13 & $(0.33)$ & 0.003 & $(0.06)$ & 0.001 & $(0.03)$ \\
Observations & \multicolumn{2}{c}{28} & \multicolumn{3}{c}{30} & \multicolumn{2}{c}{1309} & \multicolumn{2}{c}{1311} \\
\hline
\end{tabular}

Note: Standard deviations in parentheses. We also include 8 ethnicity dummies in the set of the matching variables, but we do not report their distributions to avoid cluttering the table. Results are available upon request.

Table A5. Difference-in-differences results.

\begin{tabular}{cccc}
\hline \multirow{2}{*}{ Dependent Variable } & $\begin{array}{c}(\mathbf{1}) \\
\text { Work for Others to } \\
\text { Self-Employed }\end{array}$ & $\begin{array}{c}(\mathbf{2}) \\
\text { Temporarily Employed } \\
\text { to Self-Employed }\end{array}$ & $\begin{array}{c}(\mathbf{3}) \\
\text { Unemployed to } \\
\text { Self-Employed }\end{array}$ \\
\hline \multirow{2}{*}{$P \times T$} & $0.254^{* * *}$ & $0.108^{* *}$ & -0.013 \\
& $(7.73)$ & $(2.57)$ & $(0.45)$ \\
$T$ & $-0.279^{* * *}$ & $-0.182^{* * *}$ & -0.009 \\
& $(9.19)$ & $(4.47)$ & $(0.32)$ \\
$P$ & $0.067^{* * *}$ & $0.050^{* * *}$ & 0.012 \\
& $(4.46)$ & $(3.85)$ & $(1.52)$ \\
Age & $0.003^{* * *}$ & $0.004^{* * *}$ & $0.000^{*}$ \\
& $(6.80)$ & $(10.44)$ & $(1.88)$ \\
Gender & $0.042^{* * *}$ & $0.018^{* *}$ & 0.008 \\
& $(4.01)$ & $(2.00)$ & $(1.62)$ \\
\hline
\end{tabular}


Table A5. Cont.

\begin{tabular}{cccc}
\hline Dependent Variable & $\begin{array}{c}(\mathbf{1}) \\
\text { Work for Others to } \\
\text { Self-Employed }\end{array}$ & $\begin{array}{c}\text { (2) } \\
\text { Temporarily Employed } \\
\text { to Self-Employed }\end{array}$ & $\begin{array}{c}(\mathbf{3}) \\
\text { Unemployed to } \\
\text { Self-Employed }\end{array}$ \\
\hline Education: & & & \\
Primary & -0.021 & 0.002 & 0.003 \\
& $(1.43)$ & $(0.12)$ & $(0.45)$ \\
Lower secondary & $-0.101^{* * *}$ & $-0.034^{* * *}$ & -0.004 \\
& $(6.41)$ & $(2.59)$ & $(0.47)$ \\
Upper secondary & $-0.310^{* * *}$ & $-0.055^{* * *}$ & $-0.043^{* * *}$ \\
& $(15.44)$ & $(2.96)$ & $(4.05)$ \\
University & $-0.616^{* * *}$ & 0.126 & 0.029 \\
Ethnicity dummies & $(13.49)$ & $(1.26)$ & $(0.51)$ \\
Province dummies & yes & yes & yes \\
$\mathrm{R}^{2}$ & yes & yes & yes \\
Observations & 0.24 & 0.13 & 0.03 \\
& 4053 & 4119 & 3864 \\
\hline
\end{tabular}

Note: $t$-values in parentheses. ${ }^{* * *}, * *$, and ${ }^{*}$ denote statistical significance at the $1 \%, 5 \%$, and $10 \%$ levels, respectively.

\section{References}

1. Acs, Z. How is entrepreneurship good for economic growth? Innovations 2006, 1, 97-107. [CrossRef]

2. Faggio, G.; Silia, O. Self-employment and entrepreneurship in urban and rural labourmarkets. J. Urban Econ. 2014, 84, 67-85. [CrossRef]

3. Parish, W.L.; Zhe, X.; Li, F. Nonfarm work and marketization of the Chinese countryside. China Q. 1995, 143, 697-730. [CrossRef]

4. Mohapatra, S.; Rozelle, S.; Goodhue, R. The rise of self-employment in rural China: Development or distress? World Dev. 2007, 35, 163-181. [CrossRef]

5. Wellington, A.J. Health insurance coverage and entrepreneurship. Contemp. Econ. Pol. 2001, 19, 465-478. [CrossRef]

6. Salvino, R.; Tasto, M.; Randolph, G. Entrepreneurship and the consequences of healthcare policy. J. Entrep. Public Policy. 2014, 3, 141-159. [CrossRef]

7. Fairlie, R.W.; Kapur, K.; Gates, S. Is employer-based health insurance a barrier to entrepreneurship? J. Health Econ. 2011, 30, 146-162. [CrossRef] [PubMed]

8. Gai, Y.; Minniti, M. Health Insurance, Job Lock, and the Supply of Self-Employment. J. Small. Bus. Manag. 2015, 53, 558-580. [CrossRef]

9. Ma, S.; Zhang, J. New rural cooperative medical system and household nutrient structure. Econ. Res. J. 2011, 5, 126-153. (In Chinese)

10. Wang, Y.; Ying, M.; Du, Z. The effects of medical insurance on durables consumption in rural China. China Agric. Econ. Rev. 2012, 4, 176-187.

11. Cheung, D.; Padieu, Y. Heterogeneity of the effects of health insurance on household savings: Evidence from rural China. World Dev. 2015, 66, 84-103. [CrossRef]

12. Currie, J.; Madrian, B.C. Health, health insurance and the labor market. Handbook Labor Econ. 1999, 3, 3309-3416.

13. Heimb, B.T.; Lurie, I.Z. The impact of insurance subsidies on self-employment: do state non-group health insurance regulations matter? Contemp. Econ. Pol. 2013, 31, 94-109. [CrossRef]

14. Holtz-Eakin, D.; Penrod, J.R.; Rosen, H.S. Health insurance and the supply of entrepreneurs. J. Public Econ. 1996, 62, 209-235. [CrossRef]

15. Qin, X.; Pan, J.; Liu, G.G. Does participating in health insurance benefit the migrant workers in China? An empirical investigation. China Econ. Rev. 2014, 30, 263-278.

16. Xu, K.; Saksena, P.; Fu, X.; Lei, H.; Chen, N.; Carrin, G. Health care financing in rural China: New rural cooperative medical scheme. In Technical Briefs for Policy-Makers; World Health Organization: Geneva, Switzerland, 2009. 
17. Liang, X.; Guo, H.; Jin, C.; Peng, X.; Zhang, X. The effect of new cooperative medical scheme on health outcomes and alleviating catastrophic health expenditure in China: A systematic review. PLoS ONE 2012, 7, e40850. [CrossRef] [PubMed]

18. Barber, S.L.; Yao, L. Health Insurance Systems in China: A Briefing Note; World Health Organization: Geneva, Switzerland, 2010.

19. Chen, L.; de Haan, A.; Zhang, X.; Warmerdam, W. Addressing Vulnerablity in an Emerging Economy: China's New Cooperqtive Medical Schme (NCMS). Can. J. Dev. Stud. 2011, 32, 399-413. [CrossRef]

20. Wagstaff, A.; Lindelow, M.; Gao, J.; Xu, L.; Qian, J. Extending health insurance to the rural population: An impact evaluation of China's new cooperative medical scheme. J. Health Econ. 2009, 28, 1-19. [CrossRef] [PubMed]

21. Gao, S.; Meng, X. Health and Rural Cooperative Medical Insurance in China: An Empirical Analysis. Available online: http://www.welfareacademy.org/pubs/international/policy_exchanges/asp_papers/ 1121.pdf (accessed on 14 February 2017).

22. Lei, $\mathrm{X}$.; Lin, W. The new cooperative medical scheme in rural China: Does more coverage mean more service and better health? Health Econ. 2009, 18, S25-S46. [CrossRef] [PubMed]

23. Abadie, A.; Imbens, G.W. Large Sample Properties of Matching Estimators for Average Treatment Effects. Econometrica 2006, 74, 235-267. [CrossRef]

(C) 2017 by the authors. Licensee MDPI, Basel, Switzerland. This article is an open access article distributed under the terms and conditions of the Creative Commons Attribution (CC BY) license (http:/ / creativecommons.org/licenses/by/4.0/). 